\title{
Assessing Information Ergonomics in Work by Logging and Heart Rate Variability
}

\author{
Jussi Okkonen ${ }^{1, *}$, Tomi Heimonen², Reijo Savolainen', Markku Turunen¹, \\ ${ }^{1}$ University of Tampere, FIN-33014 University of Tampere, Finland \\ \{jussi.okkonen, reijo.savolainen, markku.turunen\}@uta.fi \\ ${ }^{2}$ University of Wisconsin - Stevens Point, 2100 Main St, Stevens Point, WI \\ 54481, United States \\ \{theimone\}@uwsp.edu
}

\begin{abstract}
Maintaining performance in ubiquitous work environment is increasingly dependent on the quality of physical, cognitive and organizational ergonomics of work. Since digital work environment is the reign of most knowledge workers, there is a need to elaborate the study of work ergonomics by devoting attention to the particular issues of information ergonomics in the field of HCI, too.

The paper introduces the concept of information ergonomics (IE) and operationalizes it by specifying measures used in a field study on knowledge work. The empirical data were gathered from 35 participants. The material consists of application log data of $\mathrm{PC}$ use and heart variability rate data. Based on the empirical findings, the study also reflects theoretical propositions for the development of IE research. The study contributes to the methodological development of IE research by elaborating tools and by operationalizing and validating measurement of IE. The findings have also practical implications.
\end{abstract}

Keywords: Information Ergonomics $\cdot$ Stress $\cdot$ Logging $\cdot H R V \cdot I n$ Situ Study

\section{Introduction}

The concept of information ergonomics has been occasionally used for several decades e.g.,[1]. Yet there is no consensus among researchers about the scope and definition of information ergonomics. Stein and Müller [2] defines the goal of information ergonomics as the optimization of information search and selection, as well as cognitive processing of text, image, sound and video-based information of information systems. Bubb [3] characterizes information ergonomics as a special branch of system ergonomics focusing on the information flow resulting from the integration of the human operator in the man-machine system, and system ergonomic design aims at the optimization of such information flows. According to Bubb [3], the main object of information ergonomics is the organization of information, the investigation of human search strategies, resulting requirements for the creation of search engines and the technical representation of the retrieved information. Franssila et al [4] define information ergonomics as set of rules of adapting environment, tasks and work in general to individual, not 
vice versa. Putting the mentioned together, the domain and goal of information ergonomics could be defined as matching human and information technology somewhat optimally.

Contemporary knowledge work environment is creating new kinds of challenges for employees. Experiences of hurry, information overload, fragmentation, loss of control, always-on expectations, attention deficit, and burnout are common. One proposition for these symptoms is that the pace of work, an abundance of information processing needs, the ubiquity of information technology appliances used for work as well as private purposes, and ill-structured working patterns are creating new pressures on human performance. Today's knowledge worker is typically deeply immersed into the digitally rich, ubiquitous work environment during most of the wake hours. Information technology has enhanced knowledge work processes, especially communication related to the work processes, in several ways. But why does this environment cause negative symptoms and disturbances of worker well-being? Or does it cause? If, what could be done to diminish the harmful effects? What is the relation between characteristics of the ubiquitous, immersive, digital work environments and work wellbeing and productivity? According to Okkonen [5] knowledge work or knowledge worker productivity is multifaceted phenomenon, that is subject to several external, as well as internal factors. Organization, conventions, infrastructure, individuals, habits are the factors that productivity and conditions that nurture productivity are dependent on.

\section{Research framework for information ergonomics - the perspective of HCI}

Ergonomics is applied multidisciplinary science devoted to the enhancement of fit between human characteristics and tools and environments of the work. It is defined as "(...) scientific discipline concerned with the understanding of interactions among humans and other elements of a system, and the profession that applies theory, principles, data and methods to design in order to optimize human well-being and overall system performance."[6]. Further, the design target of ergonomics can be either the tools used in the work, the overall work environment characteristics, or the working methods applied in the work. In the case of physical work, the analysis of the details of the work environments and work methods try to detect and control features of the work which create strain, excessive load and risks. For today's knowledge workers, the focus should not only be on the ergonomic understanding and design of knowledge work, but also on the digital conditions and techniques of knowledge work, especially on the analysis of actual information intensive, digitally embedded workspaces, computing conventions and load exposures created. This new approach to observe, design and enhance digitally rich, ubiquitous, real world work environments and work methods is called information ergonomics. While usability, user experience and HCI research seek to enhance the information technological tools and services to fit better for humans, information ergonomics directs the analytical scrutiny into complete, digitally diverse work environments and actual computing behavior, thereby connecting technological aspects with social ones. Technological aspects to information ergonomics are related, for example, to hybrid or augmented cognition, machine learning and adaptive technology just to mention some HCI related issues. 
Information ergonomics is to identify and manage information load at knowledge related work and develop methods for effectively suit different processes and conventions for individuals better cope demands of work. Information load can stem from the work content, work processes, the organization of work, work environment or the modes of action in the work community. So far, researchers have mainly approached loading factors at work in terms of cognitive load [7] and mental workload [8]. In addition, the concept of information overload has become popular since the 1980s [9]. These three concepts are closely related in that they focus on factors that set limits to human information processing capacity and are connected to wellbeing experiences at work. In general, information ergonomics is an issue of human technology interaction, socially constructed conventions and individual habits embedded to certain goal rational socio-technological system. HCI issues of information ergonomics are about process, environment, and organization of work, as well as the ones of social are about process, organization, modes of action and the ones of habits are work process, organization of work, modes of action.

Cognitive load refers to the total amount of mental effort being used in the working memory. Education scientists have concentrated on cognitive load in the context of memorizing [10] and learning [11]. So far, there is no agreed-upon definition of mental workload and it has proved one of the most nebulous concepts of ergonomics [8]. There are multiple approaches to the main determinants of mental workload. On the one hand, mental workload may be due to exogenous task demands specified by task difficulty and situational contingencies, for example. On the other hand, it may be caused by endogenous supply of attentional or processing resources to support information processing such as perceiving, updating memory, planning, decision making, and response processing [12]. Situation awareness can be regarded as the momentary content of those resources. Thus, situational awareness is a subjective state that is afforded by the object or objects of one's attentional resources [13]. Finally, information overload may be understood as a subjective experience of being overwhelmed by excessive supply of information and the insufficiency of time needed to make effective use of information resources available in specific situations [14]. Eppler and Mengis [9] demonstrated that information overload can stem from a variety of factors ranging from poor skills of personal information management to the requirements of sharing the same information through multiple channels. The load is the root cause for poor information ergonomics, yet it is determined by the other factors affecting the functionality of digital environment. Figure 1 describes the components and perspectives of information ergonomics. 


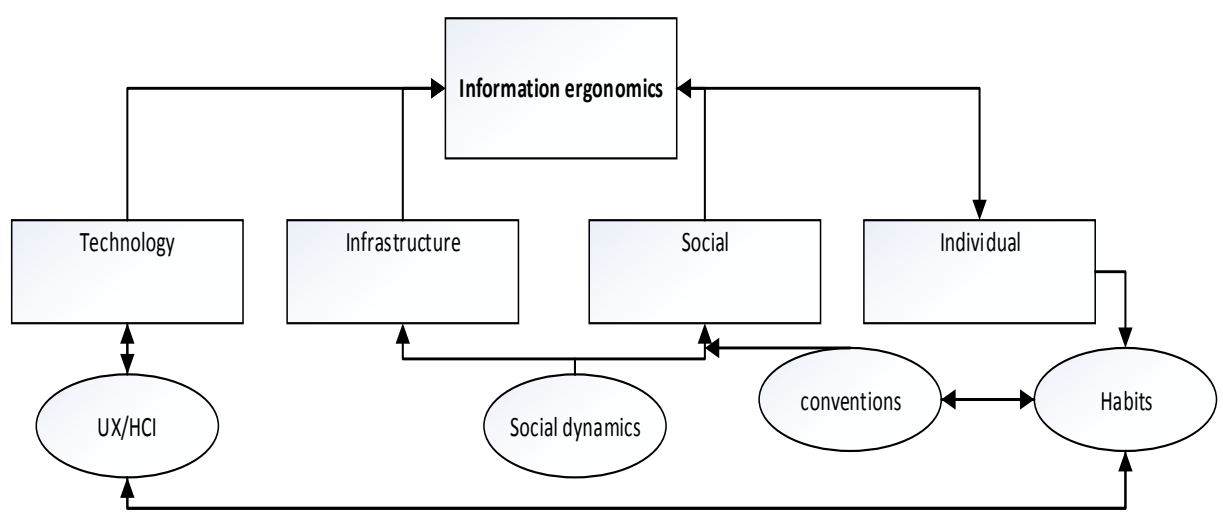

Figure 1. Components and perspectives to information ergonomics

Technology related issues of information ergonomics consider interaction with different digital tools, systems and information channels, e.g. communication as discussed in [17]. Technology affects both human-computer interaction as well as human-human interaction. Themes of usability and user experience are topical in this context, yet low level of information ergonomics nor dysfunctionalities cannot be reduced to those. As depicted above, conventions and habits, as well as individual skills, affect how individual positions oneself in digital environment and how the digital environment affects the performance. Moreover, the role of technology in this context too is dominant, as it defines the framework and functional boundaries.

Infrastructure related issues of information ergonomics consider socio-technological system that is somewhat manageable through applications and by instructions. Infrastructure consists of physical and digital environment, hardware and software, and intentions on purposeful use of those assets. Infrastructure affects ergonomics directly as technological restraint and via social factors. Social factors of information ergonomics affect vicariously as those are the products of interplay between individuals in digital environment. On the other hand, social factors can be seen as socially constructed conventions and set of explicit and implicit contracts. Social factors and infrastructure are closely of kin, but distinction should be made. Some infrastructural factors have very precise role and some social factors have not. For analytical purposes it is more useful to have two categories.

Individual factors of information ergonomics are the most obscure elements and variable too. The (micro) actions and decision individuals conduct and make during their active hours are dependent on the nature of the task and the work environment. As the work is more about managing and analyzing information, the most significant factor is digital work environment. There is two-way effect. Digital environment has effect on how individual works and how the resources are utilized. On the other hand, individual has own habits of using digital resources, thus he/she has effect on the environment.

To put above together, information ergonomics is issue of how user interacts with digital environment and by digital environment. The skills and habits are crucial factors for user experience, thus UX issues explain the functionality of human-computer apparatus. As the nature of knowledge work is about gathering, analyzing and disseminating 
information and knowledge, digital work environment is also tool for cooperation and communication. Communication structure and mutual exchanges between different actors within the digital environment form other set of interaction schemes. The following empirical examination of the topic is for the positioning information ergonomics in the field of HCI research and for validating the components of it.

The characterizations exemplify an information appliance and software oriented perspective on information ergonomics. To elaborate that viewpoint further information ergonomics is approached as a sub-field of ergonomics focusing on informational, organizational and cognitive aspects of information-intensive work processes and observable behavior in the digital work environment and overall behavior in the digital work environment. From the informational point of view, the main attention is directed to the information resources and ICT tools available in the work environment, as well as the ways in which individuals manage information load and orient themselves while performing work tasks supported by such resources and tools. The organizational viewpoint focuses on norm and rule-based factors affecting the ways in which tasks are performed in the work community and how the workers communicate with each other. Finally, the cognitive viewpoint concentrates on the ways in which an individual's cognitive resources and abilities such as memory, tolerance for interruptions and juggling multiple tasks affect the information-intensive work processes. Understood this way, information ergonomics is a legitimate and autonomous application domain of ergonomics.

\section{Related work}

Assessing working conditions and developing work environment is currently topical issue in psychology, HCI, business economics and information studies. All disciplines have common interest on reliable and practical assessment of enablers and restraints of work. On user level, the measurement problem can be reduced to measuring stress and measuring triggering conditions.

\section{Measurement of cognitive load and stress}

One of the key topics is how to assess load and stress caused by different working conditions. As discussed in Sullivan et al [16] measuring productivity in knowledge work is issue of assessing enablers and restraints. Performance in knowledge work is sum of several factors and quite difficult to measure only by the outcomes [5]. Moreover, if knowledge worker is set under the focus the assessment is more difficult, since intangible work processes are hard to capture, or there are several simultaneous processes on going. Therefore, the productivity issue in knowledge work should be addressed from different angle. What if the key was the ease of working? Being in in flow is such stage when person has low stress and feeling of self-efficacy and achievement. The concept of flow originated from Csikszentmihalyi's [17 and 18] research on the psychology of optimal experience, or the study of happiness, fun and well-being. Optimal experience is defined as "a deep sense of enjoyment that is long cherished, [that] does not come through passive, receptive, relaxing times" [18]. The term flow is also used to represent this feeling of complete engagement and immersion in an activity. It 
is widely noted that during a state of flow, people lose track of time and are completely focused on the activity at hand, commonly referred to as 'being in the Zone' [19]. Taking this into account the cognitive load and stress should be measured in order to better understand ergonomics of knowledge work. Stress can be seen as a manifestation of change cognitive, emotional or physiological state, i.e. any load causes stress.

There are several methods for assessing stress and cognitive load. Methods can be roughly divided to subjective methods and objective methods. The key difference with those two are the different measurement time, i.e. before, after or during action and thoroughness, practicality or intrusiveness of measurement method.

Subjective measurement is based on subject-generated data that is gathered during or after action or certain period. Typical way of acquiring such data is to interview, diaries or surveys. Such methods are easy to implement, yet main shortcoming is to connect results with certain event [e.g. 20,21]. Moreover, subjective measurement are sensitive to certain episodes and they tend to measure peak effects.

Measuring stress by monitoring devices such as electrodermal activity (EDA) or heart rate variability (HRV) are continuous methods to measure cognitive load or stress over time $[22,23]$. Especially HRV is widely used in measurement in different settings [e.g.24, 25, 26, 27, 28, 29]. According to previous studies HRV can be used to along other methods and due to nature of data HRV measurement results are somewhat easily connected to results of other means of inquiry. Moreover, HRV is validated method for $\mathrm{n}$ such use and widely used in $\mathrm{HCI}$ research.

\section{Assessing digital work environment}

Digital work environment consist of different applications person uses daily in work. Digital refers also computer mediated communication and using for example smart phone for daily chores. Researching digital work environment is an issue of practicality. It can be addressed from the perspective of subjective assessment by the worker [13]. Such methods can be used in ergonomics research and they provide thorough overview on the environment $[4,30,31,32]$. However, such methods often concentrate on indirect factors and job satisfaction and actual work flow is not made visible.

Direct digital work environment assessment refers observing and recording work process and acts in digital environment. Shadowing refers to being physically present and observing actions [33]. Such method grants access to process, yet may be very intrusive and distracting. Such bias caused by researcher can be diminished by using recording such as lifelogging camera or screen video $[34,35]$. Burden of such methods is the quantity of unstructured data that has to be codified before it can be connected with other data. Moreover, there are also sensitivity and security issue as everything user sees is also visible to researchers. Digital environment can be also tracked by suitable software or applications $[4,36]$. Activity logging provides accurate data on digital actions. Such data can be used for quantifying usage of different applications or tracking different types of tasks. Tracking operating system or user interface also provides logical samples of all actions in digital working environment. 


\section{Research setting and data}

The empiric research for this paper consists of series of field studies in three knowledge work organisations $(n=37)$. The domains of the organisations were financial management $(n=13$, insurance $(n=14)$, payroll management $(n=10)$. The test subjects were chosen by convenience sampling, i.e. they were voluntary adults recruited by HR personnel in respective organisation. The sample consisted of 35 female and 2 male subjects. Skewness is not considered an issue, since subjects are not compared according to gender.

All participants worked with data and information management related tasks with office applications or by browser user interface. 24 of the participants had direct customer contacts with external or internal customers. Contacts were either by email, telephone or specific communication applications such as Lync.

The data was gathered as a part of extensive research project in which knowledge workers were examined. The overall topic was to see how customer value is created and leveraged through enhanced information ergonomics. The original research setting consisted of three subprojects that were conducted uniformly. In addition to tracking and HRV data also background surveys, subjective measurements of stress, work performance, and mindfulness were gathered on respective days. Several group interviews and development workshops in each organization served as tool for delivering feedback and also for reflecting the findings.

The measurement of HRV was conducted by using Polar H7 heart rate monitor [37] and CardioMood for Android [38]. Each person was rigged in morning with heart rate monitor and they had an android phone with them to record the data. During the day the subjects filled morning and afternoon surveys about their digital work environment and they also assessed the sense of control and achievement at the end of their working day.

The digital work environment was logged by ManicTime [39] timetracking software for PC. The software records active applications and documents and it makes it possible to track all shifts and record the time of each work sequences. For futher analysis ManicTime enables to categorize different applications in sense to see the time and duration of certain task types.

The recording of HRV and tracking was applied for one working day per participant. Mean recording duration was 7 hours 56 minutes. Shortest recording was 4 hours and 56 minutes and the longest was 13 hours 47 minutes. The recording of HRV was on for all the time. Active tracking data covers $25 \%$ to $89 \%$ while mean was $69 \%$, since idle time on PC was considered as a break. Idle time is tagged by the software and labeled by the users, so meetings, recreation and other non-active time is also available for analysis.

\section{Results}

The ManicTime data and the HRV recordings were analyzed to identify correlations between the measures. The first task was to match up the recordings based on timestamps. 16 participants were excluded from further analysis due to missing ManicTime data ( 2 participants) or lack of sufficient overlap between the HRV and 
ManicTime recordings to allow for reliable analysis. Further work is needed to complete the data set, but even now the data is sufficient for exploratory analysis.

For the resulting 19 participants, stress index values were calculated from the HRV recordings using a two-minute window size using the $50 \mathrm{~ms}$ histogram method $\mathrm{SI}=$ Amplitude of Mode / ( 2 * Mode * Variance) [40]. The resulting stress index is limited at zero. Normal stress index range is between $40-150$, with values larger than 150 indicating a stressed condition [41].

Two measures were calculated from the ManicTime data: average duration of application usage per time window and number of application switches per time window. Average duration takes into account every application or document switch and presents it over time

Exploratory data analysis was performed by examining the data across all participants to identify overall correlations between the SI measures and the application usage metrics. The analysis is based on simple metrics and it does not take into account the nature of task or purpose of application.

During analysis, outliers were removed from the SI values and average application usage duration using a $1.5^{*} \mathrm{IQR}$ (Interquartile Range) threshold. In the case of the stress index this was necessary due to inflated values that may be an artifact of the data collection and calculation procedure.

The Pearson product-moment correlation between the number of application switches and stress index was $0.064, \mathrm{p}<0.001$ (Figure 2). This was an unexpected results, yet due to an extreme general view on the measured sequences.

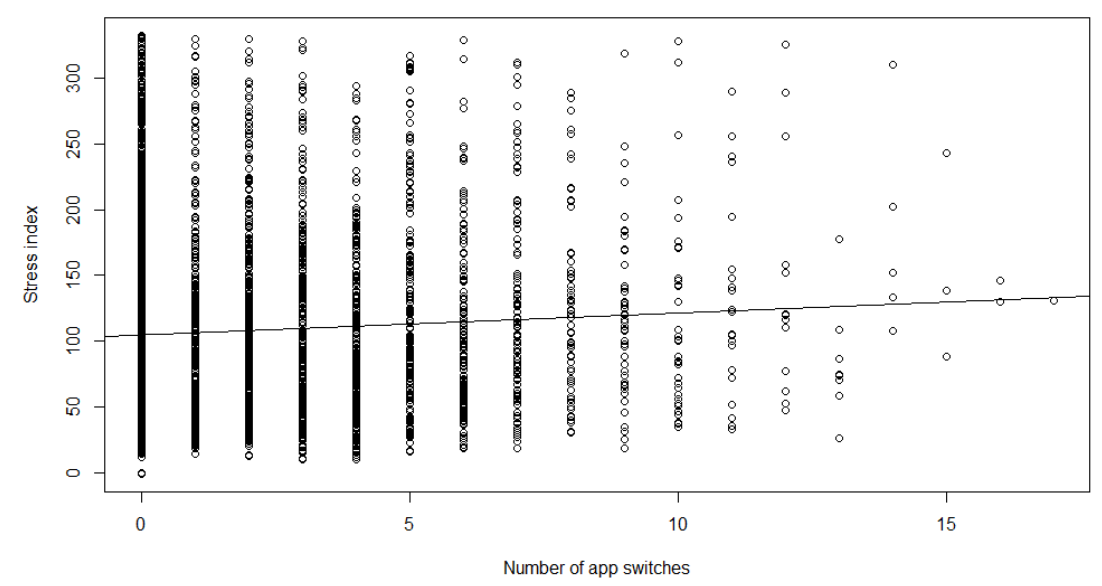

Figure 2. Correlation between application switches and stress

The correlation between the average application usage duration and stress index was -0.058 . $p<0.05$ (Figure 3). This was expected as stated above: short work sequences are forecasting low control on tasks and low sense of control that are connected to cognitive load and stress. 


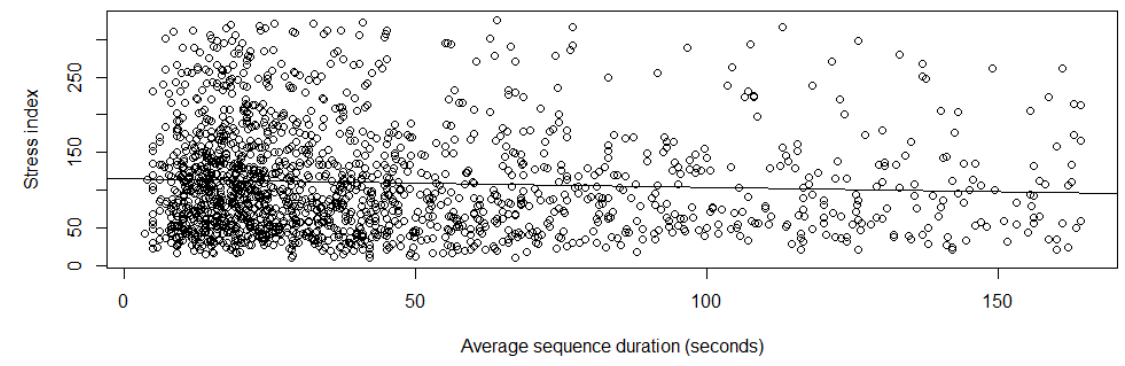

Figure 3. Correlation between work sequence duration and stress

Together, the correlations suggest a weak relationship between the frequency and duration of application usage sequences and experienced stress. The correlation between task sequence duration and stress index is as expected, i.e. shorter usage periods and higher stress levels coexists. Further analysis is needed to verify the initial pattern, using different time window sizes. Additional manual pruning and cleansing of the ManicTime and HRV recordings is also necessary to better synchronize the datasets. Moreover, the data should be split and reorganized, since now all stress index values are compared to all events. Some sequences should be removed as outliers such recreational breaks, face-to-face meeting, etc. are within the data.

We are also planning a more detailed analysis of the stress index time series data to simplify the model, by looking at stress level decrease/increase as a function of application usage sequences. Initial visual analysis of the overlaid stress index and application switches also suggested a delayed pattern in the stress level changes and application usage. The analysis did not pay attention to task types either, so more thorough classification on purpose of certain applications, e.g. information management, information refining, or communication, is necessary to conduct before further analysis drawing the conclusions. More advanced modeling techniques (e.g., lagged correlation) are likely needed to explore the true relationships between the measures.

Preliminary qualitative analysis based on comparing graphs visually brought about a lag after shorter or decreasing work sequences and increased stress levels, thus lagged correlations and changes in digital environment is the next phase in analyzing this data. Other qualitative finding was that all participants had higher stress levels in afternoon and that is another interesting observation to research further.

\section{Discussion}

The connection between stress and events in digital environment are in correlation. The proposition presented above was that when person can work on pace and methods one is accustomed to, the ease of working and having a flow experience is measurable by low stress level. On the other hand changing tasks or changing task types are triggering conditions for increased stress level. The findings do not propose that multitasking or change during the day have necessarily ill effect, but cause increased stress. The 
analysis was insensitive to interruptions in sense the events were not categorized according to those. At least external interruptions, e.g. incoming email, messages or phone calls, should be extracted since cause significant distraction in the work flow. On the other hand the self-inflicted interruptions or non-moderated digital work environment seem to cause stress [15,27]. Distilling such events for further analysis is needed in order to have more thorough picture on actual causes of stress in digital environment.

As described above the data is extracted from larger data set and data-triangulation is required. The subjective assessment of stress, mindfulness, self-efficacy, and sense of achievement should be taken into account when further analyzing workflow and stress.

The data consists of tracking computer and there are obvious gaps in data as people have also possibility to use their smart phones. For most of the participants the use of smartphone for work was not extensive, yet possible. Moreover, using smartphone is recorded in some occasions and in some occasions it is not, so having completed view on smart phone usage there is still much work to be done. One key topic related to using smart phone is the situations and space. Many participants reported that they use it outside the office hours for checking email or planning work by a calendar. Obvious shortcoming with this research setting was limiting to a single day and tracking only personal computer.

The exploratory analysis of measurement data reveled several new issues to be addressed and the result are not conclusive. The results contribute to the methodology of researching people working in digital environment. The methodological contribution to the field of work ergonomics is also substantial, since now the next step in assessing and analyzing individuals in wild is taken. The paper presents new way to analyze ergonomics in knowledge work.

The practical implications of applying HRV and tracking for researching digital environment are twofold. Firstly, as discussed in related work and the presented in empiric part, such method is useful for researchers and practitioners to investigate dynamics of digital work environment. The tracking itself could be sufficient if load and stress could be easily connected to certain events, yet practicality of subjective assessment is somewhat low and it causes unwanted distraction. The second practical implication is that comparing tracking and HRV with other methods it is possible to have large samples that are easily managed and analyzed. If tracking data would have been substituted for example by screen video, the organization and categorization would have required extensive amount of work.

\section{References}

1. Ivergård, T. (1969) Informationsergonomi. Stockholm, Sweden: Rabén \& Sjögren.

2. Stein, M., and Müller, B. H. (2003) Informationsergonomie - Entwicklung einer Checkliste zur Bewertung der Nutzerfreundlichkeit von Websites. In Psychologie der Arbeitssicherheit und Gesundheit, 12. Workshop 2003, edited by H-G. Giesa, K-P. Timpe, and U. Winterfeld, 41-44. Heidelberg, Germany: Asanger Verlag.

3. Bubb, H. (2012). Information Ergonomics. In Information Ergonomics. A Theoretical Approach and Practical Experience in Transportation, edited by M. Stein, and P. Sands, 23-57. Berlin: Springer. 
4. Franssila, H., Okkonen, J., Savolainen, R. (2015). Developing measures for information ergonomics in knowledge work, Ergonomics, Vol 58 DOI:10.1080/00140139.2015.1073795

5. Okkonen, J. (2009) Measuring knowledge work performance, practical implications. Lambert Academic Publishing.

6. International Ergonomics Association. (2015) Definition and Domains of Ergonomics. Availabe at http://www.iea.cc/whats/

7. Kalyuga, S. (2011) Cognitive Load Theory: How Many Types of Load Does It Really Need? Educational Psychology Review 23 (1): 1-19.

8. Young, M.S., Brookhuis, K.A., Wickens, C.D., and Hancock, P.A. (2015) State of Science: Mental Workload in Ergonomics. Ergonomics 58 (1): 1-17.

9. Eppler, M.J., and Mengis, J. (2004) The Concept of Information Overload. A Review of Literature from Organization Science, Accounting, Marketing, MIS and Related Disciplines. The Information Society 20 (5): 325-344.

10.Murray, J., and Thomson, M.E. 2011) Age-related Differences on Cognitive Overload in an Audiovisual Memory Task." European Journal of Psychology of Education 26 (1): 129-141.

11.Renkl, A., Hilbert, T., and Schworm, S. (2009) Example-based Learning in Heuristic Domains: a Cognitive Load Theory Account. Educational Psychology Review 21 (1): 78-78.

12.Vidulich, M.A., and Tsang, P.S. (2012) Mental Workload and Situation Awareness. In Handbook of Human Factors and Ergonomics. 4th edition, edited by G. Salvendy, 243-273. Hoboken, NJ: John Wiley.

13.Charlton, S.G. (2002). Measurement of Cognitive States in Test and Evaluation. In Handbook of Human Factors Testing and Evaluation. 2nd edition, edited by S.G. Charlton, and T.G. O`Brien, 97-126. Mahwah, NJ; Lawrence Erlbaum.

14.Savolainen, R. (2008) Everyday Information Practices. A Social Phenomenological Perspective. Maryland, MD: The Scarecrow Press.

15.Mark, G., Iqbal, S.T., Czerwinski, M., and Johns, P. 2014. Bored Mondays and Focused Afternoons: The Rhythm of Attention and Online Activity in the Workplace. In Proceedings of the CHI 2014, April 26 - May 1 2014, Toronto, Canada, 3025-3034. New York:

16.Sullivan, J., Baird, G., and Donn, M. (2013) Measuring Productivity in the Office Workplace. Final Report. Wellington, New Zealand: University of Wellington. Centre for Building Performance Research

17.Nakamura, J., \& Csikszentmihalyi, M. (2002). The concept of flow. Handbook of positive psychology, 89-105.

18.Csikszentmihalyi, M., \& Csikzentmihaly, M. (1991). Flow: The psychology of optimal experience (Vol. 41). New York: HarperPerennial.

19.Chen, J. (2007). Flow in games (and everything else). Communications of the ACM, 50(4), 31-34.

20.Charlton, S.G. 2002b. Selecting Measures for Human Factors Tests. In the Handbook of Human Factors Testing and Evaluation. 2nd edition, edited by S.G. Charlton, and T.G. O`Brien, 37-53. Mahwah, NJ; Lawrence Erlbaum.

21.Clements-Croome, D., and Kaluarachchi, Y. 2000. Assessment and Measurement of Productivity. In Creating the Productive Workplace, 129-166. London, UK: E. \& FN Spon.

22. Healey, J., Pickard, R. (2005) Detecting stress during real-world driving tasks using physiological sensors. IEEE Transactions on Intelligent Transportation Systems Vol 6, Issue 2,

23. Riedl, R. (2012). On the biology of technostress: literature review and research agenda. ACM SIGMIS Database, 44(1), 18-55.

24.Pakarinen, S., Korpela, J., Torniainen, J. (2016) Quantifying acute stress with heart rate variability (HRV) and electrodermal activity (EDA) in real world conditions. in Proceedings of the 18th World Congress of Psychophysiology (IOP2016) of the International Organization of Psychophysiology (IOP) Havana, Cuba August 31st to September 4th, 2016

25.Sun, F., Kuon, C.,Cheng, H., Buthpitiya, S., Collins, C., Griss, M. (2010) Activity-aware Mental Stress Detection Using Physiological Sensors. in Mobile Computing, Applications, 
and Services Volume 76 of the series Lecture Notes of the Institute for Computer Sciences, Social Informatics and Telecommunications Engineering pp 211-230

26.Laarni, J., Karvonen, H., Pakarinen, S., Torniainen, J. (2016) Multitasking and Interruption Management in Control Room Operator Work During Simulated Accidents. in Proceedings of 13th International Conference, EPCE 2016, Held as Part of HCI International 2016, Toronto, ON, Canada, July 17-22, 2016

27.Mark, G., Iqbal, S., Czerwinski, M., Johns, P., Sano, A. (2016) Email Duration, Batching and Self-interruption: Patterns of Email Use on Productivity and Stress. in Proceedings of the 2016 CHI Conference on Human Factors in Computing Systems pp. 1717-1728

28.Haapalainen, E., Kim, S.J., Forlizzi, J.F. \& Dey, A.K. (2010) Psycho-physiological Measures for Assessing Cognitive Load. in Proceedings of UbiComp '10, 26-29 September 2010, Copenhagen, Denmark, 301-310. New York, NY: ACM.

29.Lindholm, H., Sinisalo, J. Ahlberg, J., Jahkola, A., Partinen, M., Hublin, C. and Savolainen, A. (2009) High job control enhances vagal recovery in media work. Occupational Medicine 59:pp 570-573

30.Choi, J. (2007) Change-oriented organizational citizenship behavior: effects of work environment characteristics and intervening psychological processes. J. Organiz. Behav. 28, 467-484

31.Airila, A., Hakanen, J., Luukkonen, R., Lusa, S. \& Punakallio, A (2013). Positive and negative mood trajectories and their relationship with work ability, self-rated health, and life satisfaction. Journal of Occupational \& Environmental Medicine, 55(7), 779-785.

32.Amabile, T., Conti, R., Coon, H., Lazenby, J. and Herron, M. (1996) Assessing the Work Environment for Creativity. The Academy of Management Journal Vol. 39, No. 5 pp. 11541184

33.McDonald, S. (2007) Studying actions in context: a qualitative shadowing method for organizational research. Qualitative Research vol. 5(4) 444-473

34.Blum, M., A Pentland, A., Troster, G. (2006) Insense: Interest-based life logging. IEEE MultiMedia

35.Whittaker, S., Kalnikaitè,V., Petrelli,D., Sellen, A., Villar, N., Bergman, O. Clough, P. and Brockmeier, J. (2012) Socio-Technical Lifelogging: Deriving Design Principles for a Future Proof Digital Past. Human-Computer Interaction Vol. 27 (1-2), pp. 37-62

36.Pammer, V., Bratic, M. (2013) Surprise, Surprise: Activity Log Based Time Analytics for Time Management CHI 2013 Extended Abstracts April 27-May 2, 2013, Paris, France.

37.www.polar.com

38.www.cardiomood.com

39.www.manictime.com

40.http://blog.cardiomood.com/post/112068958936/methods-of-hrv-analysis

41.http://blog.cardiomood.com/post/107832125256/how-to-check-stress-level-with-cardiomood 